\title{
МОНИТОРИНГ СОДЕРЖАНИЯ ТЯЖЕЛЫХ МЕТАЛЛОВ И ФТОРА В ПОЧВАХ СЕЛЬСКОХОЗЯЙСТВЕННЫХ УГОДИЙ УЧХОЗА «МИНДЕРЛИНСКОЕ»
}

\author{
E. I. Voloshin, V. K. Ivchenko, Yu. K. Pikulin
}

\section{MONITORING OF THE CONTENT OF HEAVY METALS AND FLUORINE IN THE SOILS OF AGRICULTURAL GROUNDS OF THE TRAINING FARM "MINDERLINSKOYE"}

Волошин Евгений Иванович - д-р с.-х. наук, проф. каф. общего земледелия и защиты растений Красноярского государственного аграрного университета, г. Красноярск.

E-mail: EV.Volochin@ yandex.ru

Ивченко Владимир Кузьмич - д-р с.-х. наук, проф. каф. общего земледелия и защиты растений Красноярского государственного аграрного университета, г. Красноярск.

E-mail: v.f.ivchenko@mail.ru

Пикулин Юрий Корнеевич - главный агроном ООО «Учхоз «Миндерлинское», Красноярский край, Сухобузимский р-н, п. Борск.

E-mail: pikulin1964@mail.ru

Учхоз «Миндерлинское» находится в Красноярской лесостепной зоне Средней Сибири и специализируется на производстве растениеводческой и животноводческой продукции. В структуре почвенного покрова преобладают черноземы и серые лесные почвы. Почвенное плодородие, валовое содержание, фоормы и степень подвижности химических элементов в почвообразующих породах и почвах во многом определяются сложностью рельефра и разнообразными условиями почвообразования. В почвах хозяйства варьирование содержания тяжелых металлов обусловлено внутритиповыми различиями при несущественных межтиповых колебаниях и характеризуется следующими усредненными величинами, ме/ке: цинк - 41,9-63,3; медь - 14,3-21,7; кобальт 10,6-13,7; марганец - 396,0-523,0; хром - 10,728,7; никель - 19,8-29,7; кадмий - 0,06-0,16; свинец - 9,5-15,0; ртуть - 0,02-0,03; фттор 0,8-5,3. Зональной особенностью почв территории хозяйства является обедненность тяжельми металлами в сравнении с другими регионами Сибири. Наиболее высокие концен-
Voloshin Evgeny Ivanovich - Dr. Agr. Sci., Prof., Chair of General Agriculture and Plants Protection, Krasnoyarsk State Agrarian University, Krasnoyarsk.

E-mail: EV.Volochin@yandex.ru

Ivchenko Vladimir Kuzmich - Dr. Agr. Sci., Prof., Chair of General Agriculture and Plants Protection, Krasnoyarsk State Agrarian University, Krasnoyarsk.

E-mail: v.f.ivchenko@mail.ru

Pikulin Yury Korneevich - Chief Agronomist, JSC "Training Farm 'Minderlinskoe'", Krasnoyarsk Region, Sukhobuzimo District, S. Borsk.

E-mail: pikulin1964@mail.ru

трации большинства тяжельх металлов отмечаются в черноземах выщелоченных $и$ обыкновенных, марганца - в серых лесных почвах. При утяжелении гранулометрического состава почв содержание тяжелых металлов и фртора увеличивается. Почвы учхоза не загрязнены тяжельми металлами и фртором, uх среднее содержание значительно ниже принятых в России стандартных норм. Результаты эколого-токсикологического мониторинга показывают, что в 2018 е. в сравнении с 2002 г. произошло незначительное увеличение содержания большинства тяжелых металлов в 0-20 см слое. Основными причинами этого является проявление водной эрозии на склоновых землях, подпахивание нижележащих горизонтов, характеризующихся более высоким содержанием токсикантов. Пониженное содержание тяжельх металлов и фртора в почвах уменьшает их биологическую доступность и, как следствие, способствует получению в хозяйстве экологически безопасной растениеводческой продукции. 
Ключевые слова: мониторине, почва, тяжелые металлы, почвообразующие породы, экологически безопасная продукция.

The training farm "Minderlinskoye" is located in the Krasnoyarsk forest-steppe zone of Central Siberia and specializes in crop and livestock production. The structure of the soil cover is dominated by chernozems and gray forest soils. Soil fertility, gross content, forms and degree of mobility of chemical elements in parent rocks and soils are largely determined by the complexity of the relief and various conditions of soil formation. In the soils of the farm the variation in the content of heavy metals is due to intra-type differences with insignificant inter-type fluctuations and is characterized by the following averaged values $(\mathrm{mg} / \mathrm{kg}$ ): zinc 41.9-63.3; copper - 14.3-21.7; cobalt - 10.6-13.7; manganese - 396.0-523.0; chromium - 10.7-28.7; nickel - 19.8-29.7; cadmium - 0.06-0.16; lead 9.5-15.0; mercury - 0.02-0.03; fluorine - 0.8-5.3. Zonal feature of the soils of the farm is the depletion of heavy metals in comparison with other regions of Siberia. The highest concentrations of most heavy metals are observed in leached and ordinary chernozems, and manganese - in gray forest soils. When granulometric composition of the soils becomes heavier, the content of heavy metals and fluorine increases. The training farm's soils are not contaminated with heavy metals and fluorine; their average content is much lower than the standard norms accepted in Russia. The results of environmental and toxicological monitoring show that in 2018, compared with 2002, there was a slight increase in most heavy metals content in arable soils in 0-20 cm layer. The main reasons are the manifestation of water erosion on sloping lands, the plowing of underlying horizons, characterized by a higher content of toxicants. Low content of heavy metals and fluorine in soils reduces their bioavailability and, as a result, contributes to receiving of environmentally friendly crop products on the farm.

Keywords: monitoring, soil, heavy metals, soil making rocks, ecologically friendly production.

Введение. Тяжелые металлы входят в группу микроэлементов и являются составной частью биосфреры. Эти элементы играют важную роль в жизни растений, так как регулируют углеводный, белковый, липоидный, фосфорный обмен и усвоение минерального азота. Как недос- таточное, так и избыточное содержание тяжелых металлов в почве приводят к снижению урожайности культур, ухудшают качество продукции растениеводства, вызывают через пищевые цепи эндемические заболевания животных и человека.

Основными загрязнителями окружающей природной среды тяжелыми металлами и фтором являются промышленные предприятия, теплоэнергетика, добыча полезных ископаемых, автотранспорт и ненормированное применение в сельском хозяйстве удобрений, химических мелиорантов и пестицидов $[6,11,12]$. Загрязненная атмосфрера - главный источник поступления токсикантов в почву. Среди тяжелых металлов к приоритетным загрязнителям агроэкосистемы относят ртуть, свинец, мышьяк, кадмий, цинк, медь, хром, никель, марганец, кобальт и другие элементы. Под их влиянием ухудшаются агрофизические, агрохимические, биологические свойства почв, снижается экологическая и экономическая ценность агроценозов.

На поведение тяжелых металлов и фттора в почве существенное влияние может оказывать наряду с условиями почвообразования, водного режима, вида растительности также и хозяйственная деятельность человека $[5,14,15]$. В связи с усилением техногенной нагрузки на агроэкосистему возникает необходимость в проведении регулярного мониторинга за содержанием и накоплением тяжелых металлов и фтора в почвах и разработке мероприятий по улучшению экологического состояния почв, повышению качества и безопасности растениеводческой продукции.

Цель исследования: мониторинг и экологическая оценка содержания тяжелых металлов и фтора в почвах сельскохозяйственных угодий учхоза «Миндерлинское» ФГБОУ ВО «Красноярский государственный аграрный университет».

Объекты и методы исследования. Учхоз «Миндерлинское» находится в Красноярской лесостепной зоне Средней Сибири и специализируется на производстве растениеводческой и животноводческой продукции. В полевых и кормовых севооборотах в хозяйстве выращиваются зерновые, зернобобовые, пропашные культуры, многолетние и однолетние травы.

Климат на территории хозяйства характеризуется резкой континентальностью. Среднемноголетняя сумма осадков составляет 365 мм, на долю зимних осадков приходится 15-25 \% годо- 
вой нормы. Среднегодовая температура ниже $0^{\circ} \mathrm{C}$. Среднемноголетняя сумма активных температур выше $10^{\circ} \mathrm{C}$ варьирует в пределах 1550 1650 0С. Глубина снежного покрова небольшая и не превышает 25-35 см. Зима продолжительная и суровая (180-200 дней). В отдельные годы почва может промерзать до 1,5-2,0 м. Летом на паровых полях после ливней и весной во время таяния снега на склоновых землях наблюдается водная эрозия почв. В весенне-летний период отмечаются засухи, которые оказывают отрицательное влияние на температурный, водный режимы почв и развитие в них микробиологических процессов. Неблагоприятное сочетание высокой температуры, низкой влажности почвы и воздуха ухудшает процессы мобилизации доступных для растений питательных веществ и оказывает существенное влияние на плодородие почвы и урожайность полевых культур.

В структуре почвенного покрова сельскохозяйственных угодий преобладают черноземы выщелоченные и обыкновенные, серые и темно- серые лесные почвы, имеющие тяжелосуглинистый и глинистый гранулометрический состав. Сложность рельефа и разнообразие условий почвообразования оказали влияние на потенциальное и эфффективное плодородие почв, валовое содержание, формы и степень подвижности химических элементов в почвах.

Эколого-токсикологическое обследование почв проводилось в соответствии с методическими указаниями [8]. Отбор смешанных образцов осуществляли из 0-20 см слоя почв на элементарном участке площадью 40-50 га. Образцы на содержание тяжелых металлов и фртора из профиля почв отбирали из разрезов, сделанных П. И. Крупкиным. Определение валового содержания тяжелых металлов в почвенных образцах проводили по методике ЦИНАО [7] на атомно-абсорбционном спектрофотометре, водорастворимого фртора с помощью ионоселективного электрода.

Результаты исследования и их обсуждение. Содержание валового цинка на территории хозяйства неодинаковое (табл. 1).

Таблища 1

\section{Валовое содержание цинка, меди и кобальта в почвах сельскохозяйственных угодий учхоза «Миндерлинское», мг/кг}

\begin{tabular}{|c|c|c|c|c|c|c|c|c|}
\hline \multirow{2}{*}{$\begin{array}{c}\text { Год } \\
\text { обследования }\end{array}$} & \multirow{2}{*}{$\begin{array}{c}\text { Площадь } \\
\text { обследования, } \\
\text { га }\end{array}$} & \multirow{2}{*}{$\begin{array}{c}\text { Кол-во } \\
\text { образцов, } \\
\text { шт. }\end{array}$} & \multicolumn{2}{|l|}{$\mathrm{Zn}$} & \multicolumn{2}{|l|}{$\mathrm{Cu}$} & \multicolumn{2}{|l|}{ Co } \\
\hline & & & $\min -\max$ & $\mathrm{x}$ & $\min -\max$ & $\mathrm{x}$ & $\min -\max$ & $\mathrm{x}$ \\
\hline 2002 & 4618 & 100 & $44,7-49,3$ & 47,8 & $14,2-17,2$ & 16,1 & $8,5-9,0$ & 8,7 \\
\hline 2018 & 4618 & 100 & $41,9-63,3$ & 53,2 & $14,3-21,7$ & 18,5 & $10,6-13,7$ & 12,1 \\
\hline $\begin{array}{l}\text { Фоновое содер- } \\
\text { жание по Красно- } \\
\text { ярскому краю [2] }\end{array}$ & - & - & - & 52,3 & - & 18,2 & - & 9,3 \\
\hline ПДКУ (ОДК) $[4,9]$ & - & - & - & 220,0 & - & 132,0 & - & 50,0 \\
\hline
\end{tabular}

На распределение цинка в пахотном горизонте почв сильное влияние оказывает пестрота в их плодородии. Различия же в распределении этого элемента в почвах обусловлены, прежде всего, низкой концентрацией в почвообразующих породах и разным гранулометрическим составом.

Установлено, что среднее содержание цинка в почвах хозяйства находится на уровне фонового содержания элемента в агроценозах Красноярского края. При проведении обследования не установлено загрязнения почв сельскохозяйственных угодий цинком. Результаты обследования свидетельствуют об отсутствии загрязнения почв сельскохозяйственных угодий этим элементом.
В почвах учхоза отмечена высокая природная вариабельность содержания валовой меди, которая составляет 1,2-1,5 раза. Она может быть обусловлена значительной пестротой почвенного плодородия и связана с различными геохимическими условиями формирования почв.

Среднее содержание меди в почвах находится на уровне фоновой концентрации элемента в земледельческой части Красноярского края. Почвы учхоза не загрязнены медью, ее концентрация в 7,1 раза ниже принятой в России санитарной нормы.

Результаты исследования свидетельствуют, что почвы сельскохозяйственных угодий учхоза не загрязнены кобальтом, концентрация которого в 4,1 раза ниже санитарной нормы. 
Содержание и распределение марганца в почве зависит от целого ряда факторов (условия почвообразования, различия в агрофизической, агрохимической характеристике почв и концентрации элемента в почвообразующих породах) (табл. 2).

На обследованной территории максимальное содержание марганца в почвах в 1,3 раза пре- восходит его минимальную концентрацию. Среднее содержание валового марганца в почвах хозяйства находится на уровне фроновой концентрации элемента в земледельческой части Красноярского края. Почвы не загрязнены марганцем, его средняя концентрация в 3,2 раза ниже принятой в России санитарной нормы.

Таблица 2

\section{Валовое содержание марганца, никеля и хрома в почвах сельскохозяйственных угодий учхоза «Миндерлинское», мг/кг}

\begin{tabular}{|l|c|c|c|c|c|c|}
\hline \multirow{2}{*}{\multicolumn{1}{|c|}{ Год обследования }} & \multicolumn{2}{c|}{$\mathrm{Mn}$} & \multicolumn{2}{c|}{$\mathrm{Cr}$} & \multicolumn{2}{c|}{$\mathrm{Ni}$} \\
\cline { 2 - 8 } & $\operatorname{min-max}$ & $\mathrm{x}$ & $\min -\max$ & $\mathrm{x}$ & $\min -\mathrm{max}$ & $\mathrm{x}$ \\
\hline 2002 & $451,8-473,3$ & 464,0 & $11,4-32,7$ & 23,9 & $9,7-28,6$ & 23,4 \\
\hline 2018 & $396,0-523,0$ & 462,9 & $10,7-28,7$ & 21,7 & $19,8-29,7$ & 24,3 \\
\hline $\begin{array}{l}\text { Фоновое содержание } \\
\text { по Красноярскому краю [2] }\end{array}$ & - & 463,0 & - & 25,3 & - & 25,6 \\
\hline ПДКУ (ОДК) [3, 4, 9] & - & 1500,0 & - & 100,0 & - & 80,0 \\
\hline
\end{tabular}

Валовое содержание хрома в пахотных почвах учхоза по результатам последнего обследования изменяется от 10,7 до 28,7 мг/кг. Учитывая среднее содержание хрома в почвах учхоза, которое составляет 21,7 мг/кг, можно отметить, что почвы хозяйства обеднены хромом, это может быть обусловлено низкой концентрацией элемента в почвообразующей породе. Содержание хрома в почвах ниже фоновой концентрации элемента на территории края и принятой в России санитарной нормы.

В почвах хозяйства отмечена неоднородность в распределении никеля в верхнем горизонте. При этом разница между минимальным и максимальным содержанием этого элемента в почвах достигает 1,5 раза. Как известно, максимальное количество никеля содержится в глинистых почвах. Среднее содержание никеля в почвах учхоза ниже фоновых значений элемента в южной части Красноярского края и санитарной нормы. Результаты мониторинга показывают, что на территории землепользования хозяйства почвы не загрязнены никелем.

Для почв учхоза характерно незначительное количество кадмия, которое обусловлено, прежде всего, химическим составом материнских пород. Поскольку кадмий является химическим аналогом цинка, его концентрация в почвенном покрове определяется теми же факторами, что и цинка. Биогенная аккумуляция этого элемента способствует тому, что в большинстве почв он накапливается в гумусовом горизонте.

Почвы учхоза характеризуются значительным варьированием валового содержания кадмия (табл. 3).

\section{Валовое содержание кадмия, свинца и ртути в почвах сельскохозяйственных угодий учхоза «Миндерлинское», мг/кг}

\begin{tabular}{|l|c|c|c|c|c|c|}
\hline \multirow{2}{*}{ Год обследования } & \multicolumn{2}{c|}{$\mathrm{Cd}$} & \multicolumn{2}{c|}{$\mathrm{Pb}$} & \multicolumn{2}{c|}{$\mathrm{Hg}$} \\
\cline { 2 - 7 } & $\min -\max$ & $\mathrm{x}$ & $\min -\max$ & $\mathrm{x}$ & $\min -\mathrm{max}$ & $\mathrm{x}$ \\
\hline 2002 & $0,05-0,09$ & 0,08 & $9,0-10,2$ & 9,6 & $0,022-0,024$ & 0,023 \\
\hline 2018 & $0,06-0,16$ & 0,11 & $9,5-15,0$ & 13,0 & $0,020-0,030$ & 0,020 \\
\hline $\begin{array}{l}\text { Фоновое содержание } \\
\text { по Красноярскому краю [2] }\end{array}$ & - & 0,11 & - & 11,4 & - & 0,022 \\
\hline ПДКУ (ОДК) [3, 4] & - & 2,0 & - & 130,0 & - & 12,1 \\
\hline
\end{tabular}


В последнем туре обследования разница между минимальным и максимальным значением кадмия в почвах составляет 2,7 раза. Средняя концентрация кадмия в почвах не отличается от фонового содержания элемента в агроценозах Красноярского края. Почвы учхоза не загрязнены кадмием. Об этом можно судить по его средней концентрации, которая ниже предельно допустимой в 18,2 раза.

Для почв хозяйства характерно изменение пространственного распределения свинца в почвах, обусловленное резкой концентрацией элемента в составе почвообразующих пород. Повышенное содержание свинца отмечается в почвах тяжелого гранулометрического состава. Различия между минимальными и максимальными значениями валового свинца в почвах хозяйства составляют 1,6 раза. Среднее содержание свинца в почвах незначительно превышает фоновые значения элемента в земледельческой части Красноярского края. Почвы хозяйства не загрязнены свинцом, его средняя концентрация в 10,0 раз ниже установленной санитарной нормы.

Почвы хозяйства различаются по содержанию валовой ртути, что может быть связано с неоднородностью и пестротой почвенного покрова. Немаловажное значение имеет гранулометрический состав почв. С утяжелением его концентрация этого элемента в почве повышается. Средняя концентрация ртути в почвах хозяйства находится на уровне фоновых значений в Красноярском крае. При обследовании не выявлено загрязнения почв ртутью.

Фтор является необходимым элементом в минеральном питании растений. Однако при высоких концентрациях этого элемента в почвах снижается интенсивность фотосинтеза, замедляется рост и развитие растений, что в конечном итоге приводит к уменьшению урожайности сельскохозяйственных культур. На накопление фртора в почвах существенное влияние оказывают выбросы промышленных предприятий, длительное внесение высоких доз фосффорных удобрений и фрторсодержащих химических мелиорантов.

В Красноярской лесостепной зоне Средней Сибири основным загрязнителем почв сельскохозяйственных угодий фртором является АО «РУСАЛ КрасноярсК». В результате техногенных выбросов алюминиевого завода в пригородной зоне г. Красноярска фтором загрязнены значительные площади сельскохозяйственных угодий [10]. При мониторинговых исследованиях биогеохимический статус токсиканта необходимо оценивать по водорастворимой форме, как наиболее миграционной и доступной для растений. Результаты эколого-токсикологического обследования показывают, что пространственное варьирование водорастворимого фтора в почвах хозяйства определяется разными условиями их почвообразования и неодинаковой концентрацией элемента в почвообразующих породах (табл. 4).

Таблица 4

\section{Содержание водорастворимого фтора в почвах сельскохозяйственных угодий учхоза «Миндерлинское», мг/кг}

\begin{tabular}{|l|c|c|}
\hline \multirow{2}{*}{ Год обследования } & \multicolumn{2}{|c|}{$\mathrm{F}$} \\
\cline { 2 - 3 } & $\min -\max$ & $\mathrm{X}$ \\
\hline 2002 & $0,8-3,2$ & 1,4 \\
\hline 2018 & $0,8-5,3$ & 1,4 \\
\hline Фоновое содержание по Красноярскому краю [1] & - & 0,9 \\
\hline ПДКУ (ОДК) [3] & - & 10,0 \\
\hline
\end{tabular}

Колебания между минимальными и максимальными значениями содержания фтора в почвах составляют 6,6 раза. Среднее содержание фртора в почвах незначительно превышает фоновое значение элемента на сельскохозяйственных угодьях края. Почвы учхоза не загрязнены водорастворимым фртором, его среднее содержание в 7,1 раза ниже предельно допустимой концентрации.

На содержание тяжелых металлов в разных типах почв влияют неодинаковые условия почвообразования и разная концентрация элемента в почвообразующих породах (табл. 5). 
Результаты периодического мониторинга содержания тяжелых металлов и фтора в основных типах почв сельскохозяйственных угодий учхоза «Миндерлинское», мг/кг

\begin{tabular}{|l|c|c|c|c|c|c|c|c|c|c|c|}
\hline Тип и подтип почвы & $\mathrm{Zn}$ & $\mathrm{Ni}$ & $\mathrm{Cu}$ & $\mathrm{Pb}$ & $\mathrm{Mn}$ & $\mathrm{Cd}$ & $\mathrm{Co}$ & $\mathrm{Cr}$ & $\mathrm{Hg}$ & $\mathrm{F}$ \\
\hline \multicolumn{8}{|c|}{2002 г. } \\
\hline $\begin{array}{l}\text { Чернозем } \\
\text { выщелоченный }\end{array}$ & 49,3 & 24,4 & 17,0 & 9,9 & 451,8 & 0,09 & 8,7 & 25,7 & 0,024 & 1,70 \\
\hline $\begin{array}{l}\text { Чернозем } \\
\text { обыкновенный }\end{array}$ & 49,0 & 23,9 & 17,2 & 9,4 & 455,0 & 0,09 & 8,5 & 23,2 & 0,023 & 1,68 \\
\hline Темно серая лесная & 48,3 & 23,0 & 14,2 & 10,2 & 468,4 & 0,08 & 9.0 & 23,3 & 0,023 & 1,01 \\
\hline Серая лесная & 44,7 & 21,6 & 16,0 & 9,0 & 463,3 & 0,09 & 8,7 & 23,5 & 0,022 & 1,05 \\
\hline Среднее & 47,8 & 23,4 & 16,1 & 9,6 & 459,6 & 0,085 & 8,7 & 23,9 & 0,023 & 1,36 \\
\hline \multicolumn{7}{|c|}{2018 г. } \\
\hline $\begin{array}{l}\text { Чернозем } \\
\text { выщелоченный }\end{array}$ & 53,4 & 24,6 & 18,7 & 13,6 & 456,2 & 0,13 & 12,1 & 21,0 & 0,020 & 1,67 \\
\hline $\begin{array}{l}\text { Чернозем } \\
\text { обыкновенный }\end{array}$ & 56,6 & 25,5 & 20,1 & 12,9 & 459,4 & 0,14 & 12,0 & 21,2 & 0,030 & 1,71 \\
\hline Темно серая лесная & 48,8 & 22,5 & 16,5 & 13,0 & 469,5 & 0,10 & 12,0 & 20,6 & 0,020 & 0,97 \\
\hline Серая лесная & 52,6 & 23,4 & 17,1 & 12,0 & 466,5 & 0,09 & 11,7 & 21,0 & 0,020 & 1,08 \\
\hline Среднее & 52,8 & 24,0 & 18,1 & 12,9 & 462,1 & 0,12 & 12,0 & 20,9 & 0,022 & 1,36 \\
\hline
\end{tabular}

В структуре почвенного покрова хозяйства преобладают комплексы маломощных и среднемощных почв. В результате механической обработки происходит смешивание гумусового и нижележащих горизонтов почв. На пахотных угодьях учхоза отмечается водная эрозия почв. Эти факторы оказывают влияние на содержание и распределение тяжелых металлов и фтора в почве.

Выводы. На содержание тяжелых металлов и фттора в почвах сельскохозяйственных угодий учхоза «Миндерлинское» оказывают влияние неодинаковые условия их почвообразования, различия в гранулометрическом составе и концентрации элементов в почвообразующих породах. Особенностью почв хозяйства является обедненность их тяжелыми металлами в сравнении с аналогами из других регионов Сибири. Пониженное содержание тяжелых металлов и фтора в почвах способствует уменьшению их поступления в растения и обеспечивает получение в агроценозах хозяйства экологически безопасной растениеводческой продукции.

\section{Литература}

1. Волошин Е.И. Содержание и распределение водорастворимого фттора в почвах Средней Сибири // Вестник КрасГАУ. 2003. № 2. C. 65-73.

2. Волошин Е.И. Содержание и распределение микроэлементов в почвах Средней Сибири // Вестник КрасГАУ. 2008. № 4. С. 2837.

3. ГН 2.1.7.2041-06. Предельно допустимые концентрации (ПДК) химических веществ в почве. М., 2006.

4. ГН 2.1.7.2042-06. Ориентировочно допустимые концентрации (ОДК) химических веществ в почве. М., 2006.

5. Ильин В.Б. Тяжелые металлы и неметаллы в системе почва-растение. Новосибирск: Изд-во СО РАН, 2012. $220 \mathrm{c}$.

6. Карпова Е.А., Минеев В.Г. Тяжелые металлы в агроэкосистеме. М: КДУ, 2015. 251 с.

7. Методические рекомендации по определению тяжелых металлов в почвах сельскохозяйственных угодий и продукции растениеводства. 2-е изд., перераб. и доп. М.: ЦИНАО, $1992.60 \mathrm{c.}$ 
8. Методические указания по проведению комплексного мониторинга плодородия земель сельскохозяйственного назначения. М.: Росинформагротех, 2003. 240 c.

9. Предельно допустимые концентрации химических веществ в окружающей среде. СПб.: Мир и семья, 2001. 896 с.

10. Танделов Ю.П. Фтор в системе почварастение. Красноярск, 2012. 146 с.

11. Cabata-Pendias A. Trace Elements in Soils and Plants. 4th Edition. Boca Raton, Fl: Crs Press, 2010. 548 p.

12. Kashulina G., de Caritat P., Reimann C. Snow and rain chemistry around the "Severonikel" industrial complex, NW Russia: Current status and retrospective analysis // Atmospheris Environment. 2014. V. 89. p. 672-682.

13. George J., Mastro R.E., Ram L.C., Das T.V., Rout T.K., Mohan M. Human exposure risks for metals in soil near a coal-fired powergenerating plant. Arch Environ Contam Toxicol. 2015; 68 (3): 451-61.

14. Toth G., Hermann T., Szatmari G., Pastor L. Maps ofheavy metals in the soils of the European Union and proposed priority areas for detailed assessment. Science of the Total Environment 565 (2016) 1054-1062.

15. Ozkul C. Heavy metal contaminationin soils around the Tuncbilek Thermal Power Plant (Kutahya, Turkey). Environ Monit Assees. 2016, 188 (5): 284.

\section{Literatura}

1. Voloshin E.I. Soderzhanie i raspredelenie vodorastvorimogo ftora $\mathrm{V}$ pochvah Srednej Sibiri // Vestnik KrasGAU. 2003. № 2. S. 65-73.

2. Voloshin E.I. Soderzhanie i raspredelenie mikrojelementov v pochvah Srednej Sibiri // Vestnik KrasGAU. 2008. № 4. S. 28-37.

3. GN 2.1.7.2041-06. Predel'no dopustimye koncentracii (PDK) himicheskih veshhestv $v$ pochve. M., 2006.
4. GN 2.1.7.2042-06. Orientirovochno dopustimye koncentracii (ODK) himicheskih veshhestv $v$ pochve. M., 2006.

5. Il'in V.B. Tjazhelye metally i nemetally $\mathrm{v}$ sisteme pochva-rastenie. Novosibirsk: Izd-vo SO RAN, 2012. $220 \mathrm{~s}$.

6. Karpova E.A., Mineev V.G. Tjazhelye metally v agrojekosisteme. M: KDU, 2015. $251 \mathrm{~s}$.

7. Metodicheskie rekomendacii po opredeleniju tjazhelyh metallov v pochvah sel'skohozjajstvennyh ugodij i produkcii rastenievodstva. 2-e izd., pererab. i dop. M.: CINAO, $1992.60 \mathrm{~s}$.

8. Metodicheskie ukazanija po provedeniju kompleksnogo monitoringa plodorodija zemel' sel'skohozjajstvennogo naznachenija. M.: Rosinformagroteh, 2003. $240 \mathrm{~s}$.

9. Predel'no dopustimye koncentracii himicheskih veshhestv v okruzhajushhej srede. SPb.: Mir i sem'ja, 2001. $896 \mathrm{~s}$.

10. Tandelov Ju.P. Ftor $\mathrm{v}$ sisteme pochvarastenie. Krasnojarsk, 2012. $146 \mathrm{~s}$.

11. Cabata-Pendias A. Trace Elements in Soils and Plants. 4th Edition. Boca Raton, Fl: Crs Press, 2010. $548 \mathrm{p}$.

12. Kashulina G., de Caritat P., Reimann C. Snow and rain chemistry around the "Severonikel" industrial complex, NW Russia: Current status and retrospective analysis // Atmospheris Environment. 2014. V. 89. p. 672-682.

13. George J., Mastro R.E., Ram L.C., Das T.V., Rout T.K., Mohan M. Human exposure risks for metals in soil near a coal-fired powergenerating plant. Arch Environ Contam Toxicol. 2015; 68 (3): 451-61.

14. Toth G., Hermann T., Szatmari G., Pastor L. Maps ofheavy metals in the soils of the European Union and proposed priority areas for detailed assessment. Science of the Total Environment 565 (2016) 1054-1062.

15. Ozkul C. Heavy metal contaminationin soils around the Tuncbilek Thermal Power Plant (Kutahya, Turkey). Environ Monit Assees. 2016, 188 (5): 284. 